\title{
En tiempos de Lope de Vega: El memorión Luis Ramírez de Arellano
}

\author{
Jesús Fernando Cáseda Teresa \\ IES Valle del Cidacos - Calahorra (La Rioja) \\ casedateresa@yahoo.es
}

Recepción: 28/03/2018, Aceptación: 13/09/2018, Publicación: 04/12/2019

\section{Resumen}

Este estudio analiza la figura a Luis Ramírez de Arellano, personaje dotado de una gran memoria, que se convirtió en enemigo de Lope de Vega y de otros autores teatrales del siglo Xvi en España. Se lleva a cabo un recorrido por su vida y los hechos más relevantes, desde sus orígenes hasta su muerte.

Palabras clave

Espańa; siglo XvII; Lope de Vega; teatro; memorión

\begin{abstract}
In the Time of Lope de Vega: The memorión Luis Ramirez de Arellano This study analyzes the figure of Luis Ramírez de Arellano, who, endowed with a phenomenal memory, became the enemy of Lope de Vega and other seventeenth-century Spanish dramatists. The article takes the form of an account of the most relevant events in his life.
\end{abstract}

\section{Keywords}

Spain; 17th-century; Lope de Vega; theater; great memory 


\section{Los Ramírez de Arellano}

La familia Ramírez de Arellano es, quizás, una de las de más relevantes y antiguas de la nobleza de este país. ${ }^{1}$ Debemos a Gil Ramírez de Arellano uno de los primeros memoriales sobre el linaje de su familia — modelo para muchos que se hicieron después-. En él señala que su estirpe procede de la casa real de Navarra y que se remonta al siglo XII, con Sancho Ramírez de Arellano, primer señor de la villa de Arellano, que fue asimismo bisnieto de Rodrigo Díaz de Vivar, el Cid Campeador. ${ }^{2}$ Dicha familia fue medrando económicamente y avanzando su influencia a lo largo de los siglos. Se situaron primero en La Rioja, en dos zonas muy concretas donde fundaron señoríos: el de Cameros y el señorío de Alcanadre, Ausejo y Murillo de Río Leza.

En el siglo XVI, uno de sus descendientes —Pedro Ramírez de Arellano-, mató por venganza, en Navarra, al señor de Berguison, quien accidentalmente en una jornada de caza, había antes ocasionado la muerte de su hermano Fernando, y huyó a la provincia de Cuenca, a la localidad de Villaescusa de Haro, donde se escondió con otro nombre, Hidalgo Benito. Su descendencia retomaría luego el noble apellido, continuando en dichas tierras la estirpe de origen navarro.

Dicha familia tuvo una interesante relación con diversos escritores a lo largo de los siglos. El ya citado Gil Ramírez de Arellano, en su búsqueda en los archivos del país de documentos que acreditaran la nobleza de su familia, encontró por accidente — en realidad el descubridor fue su enviado Juan Ruiz de Ulibarri-, en el convento de Santa Clara de Vivar, en Burgos, la copia manuscrita de Per Abbat del Cantar de Mio Cid. D. Juan Ramírez de Arellano hizo gobernador de sus tierras de Alcanadre, Ausejo y Murillo de Río Leza a Gregorio González, que bajo su servicio acabó la novela picaresca El guitón Honofre, a quien se ha atribuido también la autoría del Quijote de Alonso Fernández de Avellaneda. ${ }^{3}$ Otra miembro de la familia, sor Ana de la Trinidad, carmelita en el convento de Calahorra, escribió unas bellísimas composiciones poéticas que durante mucho tiempo se atribuyeron a Cecilia del Nacimiento, primera abadesa del convento carmelita de Calahorra, hija del rector de la Universidad de Valladolid y puesta en su cargo por Santa Teresa. ${ }^{4}$ Conocemos algunos datos relativos al parentesco de la madre del memorión Luis Ramírez de Arellano con Miguel de Cervantes: se trata de doña Luisa Garibay, su prima, a quien ayudó en alguna ocasión y con quien convivió en la casa familiar de Valladolid. Y el propio autor objeto

1. Véase a este respecto Ibáńez (1996) y también Moreno (1992).

2. Dicho memorial forma parte del proceso que lleva la familia por salir de una situación de postración económica que los atenaza, y que ha estudiado Moreno (1988).

3. Véase Cabo (1986), Cáseda (1999) y Criado (1979).

4. Véase la edición de Álvarez (1992). 
de este estudio, Luis Ramírez de Arellano, mantuvo una interesante relación de amistad, no siempre recíproca, con Lope de Vega, autor, también, de la obra teatral Los Ramírez de Arellano, ${ }^{5}$ con el que la familia intentó congraciarse por vía del encargo. En definitiva, los Ramírez de Arellano mantuvieron relaciones con diversos escritores de los Siglos de Oro españoles.

\section{Los Ramírez de Arellano en Villaescusa de Haro}

El solar familiar se amplió con la llegada a esta pequeña localidad conquense, en el xvi, de Pedro Ramírez de Arellano, huyendo de la justicia. Allí crecerá una rama de la misma cuyo máximo representante es el citado D. Gil Ramírez de Arellano, quien obtendrá gran poder político en la España de Felipe III como miembro del Consejo y Cámara de Castilla, caballero de la orden de Santiago, oidor de la Chancillería de Valladolid y eminente jurisconsulto y hombre de leyes que amasó fortuna, aunque también abundantes deudas. ${ }^{6}$

Es curioso el hecho de que otro miembro de la familia, obispo de Cuenca durante el reinado de los Reyes Católicos, Diego Ramírez, proyectara un centro de estudios superiores en la localidad, intento que frenó cuando supo de la intención del cardenal Cisneros de fundar la Universidad de Alcalá de Henares.

Villaescusa de Haro pronto notará la presencia de tan importante familia, que llegaría a llamarse el lugar de los obispos, pues en ella nacieron hasta diez, algo inaudito para villa de tan reducidas dimensiones. El actual ayuntamiento fue la casa familiar y su presencia en la historia de la localidad es muy conspicua a todos los niveles. Es precisamente allí donde nace Juan Ramírez de Arellano, hermano de D. Gil, y padre de nuestro escritor, Luis Ramírez de Arellano y de su hermano Juan Ramírez de Arellano, oriundos ambos de dicha localidad conquense.

\section{El padre de D. Luis, D. Juan Ramírez de Arellano}

Sabemos que D. Juan Ramírez de Arellano se casó con una prima de Miguel de Cervantes Saavedra, dońa Luisa Garibay, quien, por otra parte, estuvo involucrada, en junio de 1607, y en Valladolid - lugar convertido temporalmente en capital del reino por el duque de Lerma—, en el conocido duelo de Gaspar de

5. Vega (1641). Diana Martínez de Arellano, miembro de la familia, llevó a cabo su tesis doctoral sobre dicha obra teatral de Lope de Vega (1951) inédita.

6. Nació en Ocańa en 1547, fue señor de Poveda, caballero de la Orden de Santiago, oidor de la Real Chancillería de Valladolid y del Consejo y Cámara de Castilla. Casado con Catalina González de Medina, falleció en Madrid en 1618. Ver Inventario judicial de los bienes de Gil Ramírez de Arellano, y documentación diversa sobre el pleito con sus acreedores. 1618-1622. Archivo General de Andalucía: ES.41188/3//3761.9 y 3761.5 Fue él quien otorgó la licencia de impresión de la primera parte del Ingenioso hidalgo don Quijote de la Mancha, firmada por el propio Miguel de Cervantes en 1604. 7. Véase el trabajo de Millán (2009). 
Ezpeleta que ocasionó la muerte a este último. ${ }^{8}$ Gracias a los documentos judiciales sabemos que Cervantes y su familia eran vecinos de doña Luisa Garibay e incluso conocemos, a través de dichos documentos, que se llegó a acusar a algunas de las mujeres de la familia de hechos deshonestos. Miguel de Cervantes, que acudió en ayuda de Gaspar de Ezpeleta, fue detenido durante las pesquisas judiciales, para después ser liberado, como también sus familiares, al no existir pruebas al respecto.

Está muy claro, por tanto, que, a pesar de ser madrileño, la familia de Luis Ramírez de Arellano vivía en 1607 en Valladolid, donde el padre, D. Juan —al menos temporalmente- desarrolla su actividad de secretario, tras el traslado de la capital del reino. Este último servirá, durante largo tiempo, al conde de Lemos, relevantísimo mecenas de los mejores escritores de aquella época. En efecto, D. Pedro Fernández de Castro Andrade y Portugal — séptimo conde de Lemos- se rodeó durante toda su vida de los más eximios escritores. ${ }^{9}$ No es para nada descabellado suponer que fuera precisamente el marido de su prima Luisa Garibay, y padre de Luis, D. Juan Ramírez de Arellano, quien facilitara a Miguel de Cervantes Saavedra su puesto como secretario de tan importante personaje, sobrino este último —el conde de Lemos - del influyente duque de Lerma. Tras la muerte de D. Juan Ramírez de Arellano le sucederán, entre otros, los hermanos aragoneses Bartolomé y Lupercio Leonardo de Argensola y durante un tiempo el propio Lope de Vega, al servicio también del conde de Lemos. También D. Juan Ramírez de Arellano, padre de Luis, formó parte del Consejo de Indias durante tres ańos y hasta su muerte, que tuvo lugar en 1608.

El padre de Luis Ramírez de Arellano, por tanto, sirve a la nobleza de primera clase del país, viaja con el conde de Lemos a Italia, donde este último fundó la Universidad de Nápoles, se relaciona con los más destacados políticos de su tiempo y, en especial, con los escritores que habitualmente tienen trato con el mismo conde de Lemos, a los que este solía favorecer en múltiples ocasiones, y sobre todo, con el primo de su esposa, Miguel de Cervantes, además de los Argensola, Lope de Vega, Antonio Mira de Amescua, etc.

\section{Algunos datos de la biografía de Luis Ramírez de Arellano}

Sabemos que nació, junto con su hermano, en la localidad conquense de Villaescusa de Haro. Pero ya siendo muy joven entró al servicio del arzobispo de Toledo, D. Bernardo de Sandoval y Rojas, del que fue secretario y mayordomo. Más tarde serviría al propio duque de Lerma, D. Francisco Gómez de Sandoval y Rojas, tal vez el personaje más influyente de su tiempo. Luego sería secretario de su familiar el conde de Aguilar.

8. Una buena aproximación a aquellos hechos se encuentra en Canavaggio (1997).

9. Casás (1945). 
Resulta muy probable que en Toledo conociera a la que sería su esposa, Catalina de Toledo, de noble familia también, ${ }^{10} \mathrm{y}$ con la que tuvo, que se sepa, al menos una hija, Ana María Ramírez de Arellano y Toledo, de la que conservamos un expediente de linaje que promovió una vez muerto su padre. ${ }^{11}$

No debería confundirse a este Luis Ramírez de Arellano con otro familiar, de igual nombre, de la rama sevillana, que fue militar; ${ }^{12}$ ni tampoco con un fraile mercedario que se convirtió en la máxima dignidad de su orden, sirviente en el establecimiento de Zaragoza. ${ }^{13}$

Luis Ramírez de Arellano fue sin duda cómplice —en mayor o menor medida - de la mayor operación de corrupción política que vivió este país en toda su historia. De hecho, el duque de Lerma aprovechó su situación de privilegio para atesorar riquezas incontables gracias a su control absoluto sobre Felipe III, un rey sin capacidad para gobernar. ${ }^{14}$ Durante los años de 1599 a 1618 quien gobernó de facto el país y sus enormes posesiones fue el duque de Lerma con su secretario y mayordomo particular, Luis Ramírez de Arellano. La situación de privilegiada atalaya en que se situó le permitió por tanto compartir secretos, mirar por encima del hombro a los demás, sin importar su clase o condición, y participar de la corrupción — en una medida difícil de valorar- a que me he referido y que consistió, como absoluto despropósito, en trasladar hasta dos veces la capital del reino, de Madrid a Valladolid y viceversa, habiendo comprado previamente el duque de Lerma terrenos y palacios a precio de saldo que luego vendió por una cantidad mucho más elevada a la misma corona. Así, con esta operación de ida y vuelta, en solo seis años, acumuló Francisco Gómez de Sandoval y Rojas un patrimonio tan enorme que lo convirtió en el hombre más rico de España. Se dijo que con solo sus recursos se podía construir hasta seis veces el monasterio del Escorial.

Cuando en 1618 cayó el duque de Lerma, debacle propiciada por la reina Margarita tras la desgraciada expulsión de los moriscos en 1609, que costó una grave crisis económica con suspensión de pagos incluida, este encontró inmunidad en su estrenada condición de cardenal que el propio Felipe III permitió. A

10. Doña Catalina Manuela de Toledo y Enríquez, aparece en algunos documentos como hija de D. Alonso de Toledo y Mendoza, y de doña María Enríquez de Guzmán, casada con D. Luis Ramírez de Arellano. (VV.AA 1930: 80).

11. «Partida de bautismo de Ana María hija de Luis Ramírez de Arellano y Catalina de Toledo. Certificación de 1780». Archivo Histórico de la Nobleza, Signatura: FERNAN NUNEEZ, C.2118, D.32. Tiene fecha la solicitud original de 1647.

12. Así aparece dicho Luis Ramírez de Arellano en «Pleito hecho y causado por Luis Ramírez de Arellano, teniente mayor de Sevilla contra Catalina Porcel de Haro, mujer y conjunta persona de Juan Ortiz de Landázuri, familiar del Santo Oficio, sobre haber cometido delito con un baldrés». Ver Archivo Histórico Nacional Signatura: CONSEJOS, 25504, Exp.1.

13. Las Constituciones sinodales del obispado de Barbastro se refieren al Padre Maestro Fray Luis Ramírez de Arellano de la Orden de nuestra Señora de la Merced, Zaragoza (1656: 163).

14. Especialmente atractivo para conocer al duque de Lerma es el trabajo de Alvar (2010). 
pesar de ello, algunos de sus más fieles colaboradores, como Rodrigo Calderón de Aranda pagaron con la vida en 1621 en ejecución pública en la Plaza Mayor.

A partir de entonces, Luis Ramírez de Arellano, una vez perdida su posición de privilegio, se ve obligado a buscar otras fuentes alternativas de ingresos. Y lo hará como secretario del duque de Aguilar, ${ }^{15}$ familiar con el que comparte apellidos, y también con su actividad en un negocio que, entonces, mueve mucho dinero: el teatro.

\section{El negocio teatral y los memoriones: los piratas de las tablas escénicas}

Sabemos que con la llegada de Lope de Vega el teatro se convierte en un excelente negocio para actores y compañías, autores y propiciadores del fenómeno teatral. Al constituir casi el único espectáculo público al que las gentes acuden en masa, los teatros madrileños y de otras ciudades se llenan, lo que supone excelentes beneficios para el corral de comedias de La Pacheca, del Príncipe o de La Cruz. Lope y otros autores deben escribir a la carrera numerosas obras porque es tal la vorágine de estrenos que se dan, y tanto el deseo de novedades por parte del público, que el negocio requiere constantes obras de los mejores autores de la época, y en especial, del afamado escritor madrileño. Pero muchas de esas obras pasan directamente del autor a los actores, sin imprenta de por medio, y se acabarán extraviando: una multitud de ellas no nos ha llegado a pesar de que sí conocemos sus títulos, casi lo único de ellas que ha llegado hasta nuestros días. Pero lo que más aterrorizaba a los autores, de lo que se quejan en más de una ocasión, es de los memoriones. Los dos más importantes de la época fueron, sin duda, el de la Feliz Memoria, o Gran Memoria, don Luis Ramírez de Arellano y su hermano, Juan Ramírez de Arellano, o Memorilla, peor dotado para ello.

Aunque conocemos otros nombres, estos dos fueron sin duda los más conspicuos piratas de los textos teatrales de la época, el periodo con mayor actividad de composición literaria para las tablas escénicas. Contamos con dos testimonios que son quejas de Lope de Vega y de Cristóbal Suárez de Figueroa. En la Plaza Universal de todas ciencias y artes señala este último lo siguiente:

Llámase Luis Remirez de Arellano, hijo de nobles padres, y natural de Villaescusa de Haro. Él toma de memoria una comedia entera de tres veces que la oye, sin discrepar un punto en traga y veros. Aplica el primer día a la disposición; el segundo a la variedad de la composición; y el tercero a la puntualidad de las coplas. De este modo encomienda a la memoria las comedias que quiere. En particular tomó así la Dama Boba, el Principe Perfecto, y la Arcadia, sin otras. Estando yo oyendo la del Galán de la Membrilla que representaba Sánchez, comenzó este autor a cortar el argumento y a interrumpir el razonado, tan al descubierto, que obligó que le preguntasen de qué procedía semejante aceleración y truncamientos, y respondió

15. Según Álvarez (1790: 412). 
que de estar delante (y seńalole) quien en tres días tomaba de memoria cualquier comedia, y que de temor no le usurpase aquella la recitaba tan mal. Alborotose con ello el teatro y pidieron todos hiciese pausa, y en fin hasta que se salió de él Luis Ramírez, no hubo remedio de que se pasase adelante. ${ }^{16}$

En el prólogo a la Trecena parte de las comedias, Lope de Vega se lamenta así — sin poner el nombre e incluyendo solo el apodo— de ambos hermanos:

A esto se añade el hurtar las comedias estos que llama el vulgo, al uno Memorilla, y al otro Gran Memoria, los cuales, con algunos versos que aprenden, mezclan infinitos suyos bárbaros, con que ganan la vida vendiéndolas a los pueblos y autores extramuros: gente vil, sin oficio, y que muchas veces han estado presos. Yo quisiera librarme de este cuidado de darlas a luz, pero no puedo, porque las imprimen con mi nombre y son de los poetas duendes que arriba digo. Reciba, pues, el lector esta Parte, lo mejor que ha sido posible corregirla, y con ella mi voluntad, pues sólo tiene por interés que lea estas comedias menos erradas y que no crea que hay en el mundo quien pueda tomar de memoria una comedia viéndola representar, y que si le hubiera, yo le alabara y estimara por único en esta potencia, aunque le faltara el entendimiento, porque raras veces se hallan juntas por opinión del Filósofo, confirmada de la experiencia. ${ }^{17}$

Resulta curioso el tono de amargura y, sobre todo, el desprecio con que trata a estos individuos. Sabe muy bien Lope de Vega quiénes son los citados, pero no quiere ponerles nombre, volcando mentiras sobre ambos: ni son gentes sin oficio, ni han sido presos ni tampoco son gente vil. Son, en definitiva, nobles, no como el plebeyo Lope, que pueden impunemente llevar a cabo su propósito.

Pero es que, para entonces, Lope ya ha compuesto su obra de teatro Los Ramírez de Arellano ${ }^{18}$ que es una exaltación del linaje familiar de la familia del Gran Memoria y del Memorilla. Y además, en el mismo destino que el padre de Luis, ha estado al servicio del conde de Lemos. Y, en el colmo de los despropósitos, sabemos que el propio Lope hubo de recurrir — de forma consentida— a los dos hermanos (Gran Memoria —Luis-y Memorilla - Juan-), incorporando a sus obras la copia que estos llevaron a cabo tras aprenderla de memoria.

Por suerte, se conservan en la Biblioteca Nacional de España dos manuscritos copiados de la mano de Luis Ramírez de Arellano, su hermano y otros, de La dama boba y de El príncipe perfecto, lo que ha permitido a Víctor Dixon compararlos con la obra original de Lope, valorar así las palabras antes citadas del escritor madrileño, y llegar a la conclusión de que fue el propio Lope quien reprodujo en la edición de sus obras textos del memorión para evitar que se le adelantaran en la edición y perder, de este modo, pingües ingresos: "Emplea para ello los textos que consigue recobrar, ya que ha vendido sus 'originales' a los

16. Suárez (1615: 237).

17. Vega (1869, XXII del tomo IV).

18. Vega (1641). 
actores que los estrenaron, y en su vida guardó traslado", según dice (con cierta exageración acaso) en el prólogo a su Decimaséptima Parte. ${ }^{19}$

La aparición en 1603 de una edición «pirata» — sin su permiso— que dio importantes beneficios a sus autores le puso alerta sobre la conveniencia de editar sus propias obras. Pero se oponía un obstáculo: ya las había vendido a las compañías de actores y no disponía de los textos. Fue el duque de Sessa quien le proporcionó numerosas de ellas, que había ido coleccionando; pero aun así, faltaba una irrenunciable: La dama boba. Ello explica que echara mano de la versión memorizada por Luis Ramírez de Arellano, que todavía se conserva en la Biblioteca Nacional, procedente de la colección de Agustín Durán.

Dicho manuscrito cuenta con la firma de Luis Ramírez de Arellano al final del mismo y las iniciales de su hermano Juan, también en la última hoja. En su interior, aparecen las abreviaturas «D. 1 . Rz A» $\mathrm{y}$ «D. J. Rz A».

Se conserva también el manuscrito de El príncipe perfecto, de Lope de Vega, en la copia memorística de Luis Ramírez de Arellano, de su mano, con las firmas de Philipe Conté de Montoya y de aquel. Paz y Meliá, al referirse a dicho texto, señala:

Copia que perteneció a D. Luis Ramírez de Arellano. Licencia de Zaragoza a 28 de noviembre de 1616 y firma de Lope de Vega con fecha 23 de diciembre de 1614, imitada probablemente por Philipe Conté de Montoya, cuya letra se ve en la portada del acto tercero. ${ }^{20}$

Según Alejandro García-Reidy, en el texto encontramos hasta nueve manos diferentes que responden a otras tantas caligrafías. Según este investigador, ello demuestra cómo los Ramírez de Arellano se ayudaron de otras personas para la escritura de los textos memorizados. La labor de estos memoriones, por tanto, fue mucho "más colaborativa de lo que venimos pensando", en palabras de GarcíaReidy. Luis Ramírez de Arellano se ayudó con toda probabilidad de notas que iba tomando durante las representaciones, que servían de base a su memoria. Pero para García-Reidy resulta todavía más sorprendente el hecho de que fuera la propia companía de actores, de Riquelme, la que luego compró el texto a Luis Ramírez de Arellano: «¿Qué podemos concluir de todo esto? Que, sorprendentemente, un manuscrito de memorión acabó en manos de la compañía a la que había hurtado de oído la comedia, y aparentemente poco después de que se preparara: si la comedia se estrenó a principios de 1615, ya en 1616 — a más tardar- la tenía Riquelme, como demuestra el reparto. Podemos descartar la posibilidad de que hubiera estado en manos de Antonio de Granados y que Riquelme lo recuperara tras llegar a un acuerdo con él a principios de 1617. Antonio de Granados consiguió una copia ilegal de El príncipe perfecto de otro modo y no utilizó este manus-

19. Ver Dixon (1997).

20. $\operatorname{Paz}$ (1899: 418). 
crito. Esta copia, en cambio, fue usada por la compañía de Riquelme, que, pese a los defectos del texto, la empleó para representar». ${ }^{21}$

Curioso viaje, por tanto, de ida y vuelta, de la obra de Lope, al que fue por completo ajeno el propio autor.

No conservamos, por desgracia, copia manuscrita de la comedia La Arcadia por el memorión Luis Ramírez de Arellano, la tercera señalada por Cristóbal Suárez de Figueroa. Y sabemos, por este último, que fueron no solo estas tres citadas las que memorizó aquel, sino que fueron otras más. Pero de esta cuestión no estamos en condiciones, por ahora, de dar noticia.

Sin embargo, en el prólogo a dicha comedia de La Arcadia — dirigido al miembro del Consejo Supremo de Su Majestad, el doctor Gregorio López Madera, compañero de Gil Ramírez de Arellano, tío de Luis en dicho órgano-, Lope escribe una larga diatriba contra Luis Ramírez de Arellano, con estas palabras, a la espera, a buen seguro, de conmover al insigne magistrado y jurista:

Espero entre, otras cosas, que quien ha escrito e impreso (si bien en tan distintas y altas materias), se dolerá, de los que escriben, y que ahora tendrá remedio lo que tantas veces se ha intentado, desterrando de los teatros; unos, hombres, que viven, se sustentan y visten de hurtar a los autores las comedias, diciendo que las toman de memoria de sólo oírlas y que este no es hurto, respecto de que el representante las vende al pueblo, y que se puede valer de su memoria que es lo mismo que decir que un ladrón no lo es, porque se vale de su entendimiento dando trazas, haciendo llaves rompiendo rejas, fingiendo personas cartas, firmas y diferentes, hábitos. Esto no sólo es en dańo de los autores por quien andan perdidos y empellados; pero lo que es más: de sentir de los ingenios que las escriben porque yo he hecho diligencia para saber de uno de estos, llamado el de la gran memoria, si era verdad que la tenía, y he hallado, leyendo sus traslados que para un verso mío hay infinitos suyos, llenos de locuras, disparates e ignorancia,, bastantes a quitar la honra y opinión al mayor ingenio en nuestra nación y las, extranjeras, donde ya se leen con tanto gusto; pues si aquel antiguo poeta quebró al ollero los vaso, con el báculo, porque cantaba mal sus versos, ¿qué harán los que ven contrahacer los suyos de oro en barro?22

Según Luis Astrana Marín, en su Vida azarosa de Lope de Vega, este último decidió demandar, por fin, tras buscar el favor del citado Gregorio López Madera, a Luis Ramírez de Arellano por apropiación de sus obras, pero el resultado fue infructuoso, como señala en las palabras que se transcriben aquí:

[...] pero le quitaron la razón, diciendo que las obras eran de dominio público.

De suerte que al saqueo de que ya venía siendo víctima por parte de los «autores» $\mathrm{y}$ «mercaderes de libros», sucedía el de aquel mancebo «de la gran memoria», y aun de un pariente de este, don Juan Remírez de Arellano, que llamaban «Memorilla». ${ }^{23}$

21. García Reidy (2015).

22. Vega (1965: 117 del vol. XIII).

23. Astrana (1941: 233). 
Sin embargo, la relación entre Lope y Luis Ramírez de Arellano se calmó tiempo después, como aclara de nuevo Astrana Marín, puesto que López Madera, conocedor de Luis Ramírez de Arellano, desoyó a Lope y sus razones y este desistió. Como señala Astrana Marín, Lope intentó tiempo más tarde publicar La dama boba, no hallando el original y, entonces, "[...] tuvo que recurrir a la copia (hoy se ve que es fiel) que de memoria había transcrito Luis Remírez. Debieron por esto de hacerse muy amigos, porque nuestro paisano lo fue también de Pérez de Montalbán, quien le elogia como poeta y le llama 'el de la feliz memoria'. Remírez, al compilar sus Avisos para la muerte (1634), abrió el libro con una poesía que le entregó Lope: 'Cercado de congojas...', y después colaboró en honor del difunto en la Fama póstuma». ${ }^{24}$

¿Fue rentable la empresa? Es difícil responder a tal pregunta, pero seguro que las cuentas salieron bastante bien, a costa siempre de los beneficios de los autores, que se encontraban completamente indefensos y sin respaldo judicial o legal. Prueba de ello es el número tan elevado de copistas que referencia Margaret R. Greer, de la Duke University, en su proyecto Manos Teatrales. ${ }^{25}$ El equipo de investigadores dirigido por Greer ha tratado de recoger en un programa informático la relación de autores, obras y copistas, etc. de los manuscritos conservados. Señala a este respecto dicha profesora que aparecen varios copistas como Martínez de Mora, Matías Martínez, el pseudo Matos Fragoso, o los Ramírez de Arellano; pero son más: señal de que constituía un buen negocio. De hecho, el detallado estudio que lleva a cabo Miguel Zugasti sobre la obra El poder de la amistad de Agustín Moreto concluye que en 1654 existían dos familias textuales de la obra El poder de la amistad, con un total de doce reediciones, de las cuales al menos nueve proceden del texto fijado por el memorión. Según indica Zugasti: «La comedia, además, fue refundida en dos ocasiones: una en el siglo XVIII con el título de La amistad vence al desdén y hacer la mayor fineza (1777), y otra en el siglo XIX titulada Conseguir con el desprecio lo que no pudo el amor (1833)». ${ }^{26}$

En resumen, obtuvo más éxito el texto del memorión que el original, incluidas las diversas refundiciones de los siglos posteriores. ¿Cuál es la causa? Quizás los memoriones, en contacto directo con los editores e impresores, estaban orientados a la distribución y al negocio, puesto que sus clientes eran ellos; frente a los autores que vendían las obras a los actores y compañías. De ahí la amarga queja de Lope de Vega cuando veía que su negocio no alcanzaba las dimensiones de quienes se dedicaban simplemente a copiar sus obras.

24. Astrana (1941: 234).

25. Ver en línea <https://www.uqtr.ca/teatro/teapal/TeaPalNum07Rep/29GreerMargaret. pdf>.

26. Zugasti (2011). 


\section{De oficio: censor}

Sabemos que el tío de Luis Ramírez de Arellano, D. Gil, se empleó también como censor. Fue él quien dio su aprobación a la publicación de la primera parte del Quijote de Miguel de Cervantes, en un proceso que ha sido minuciosamente estudiado por el profesor Fernando Bouza. También conocemos a otro miembro de la familia, Diego Ramírez de Arellano, que desecha, por ejemplo, la publicación de una obra titulada Flor de sainetes, con estos argumentos:

[...] aunque en él [el manuscrito] no he visto cosa derechamente contra la fe, me ha parecido obra del todo fútil... y en gran parte inmodesta e indecente, y no solamente inútil, sino antes dañosa y totalmente indigna. ${ }^{27}$

También Luis Ramírez de Arellano, siguiendo la tradición familiar, actuó como censor de las Obras completas del dramaturgo Francisco de Rojas Zorrilla. En su aprobación, del 30 de mayo de 1639, señala lo siguiente:

APROBACIÓN DE DON LUIS REMÍREZ DE ARELLANO, EL DE LA FELIZ MEMORIA, SECRETARIO QUE FUE DEL EXCELENTÍSIMO SEÑOR DUQUE DE LERMA, ADELANTADO MAYOR DE CASTILLA. M.P.S.

Con particular gusto y atención he visto, por mandado de V.A., las doce comedias que contiene este volumen, y ha escrito don Francisco de Rojas, ingenio tan conocido, que sólo su nombre es su mayor alabanza, y los repetidos aplausos de que gozaron en los teatros de Espańa me excusan de más dilatados elogios. No he hallado en ellas cosa que sea disonante a la verdad católica de nuestra sagrada religión, ni a las más recatadas costumbres, antes muchos ejemplos morales para todos estados, y no pocos donaires dignos del buen gusto del autor. Merece no sólo que a V.A. le honre con la licencia que suplica, sino que le apremie a que pida muchas, que bien se puede usar de esta violencia con quien tiene la pluma tan bien cortada para lustre de su patria y gloria de nuestra nación.- Salvo \& c. En Madrid, a 30 de mayo de 1639. Don Luis Remírez de Arellano. ${ }^{28}$

Sorprende en dicha aprobación el elevado tono laudatorio del censor, que quizás hoy nos pueda parecer extraño, aunque no era inhabitual en la época, pues acostumbraban a ser poetas e intelectuales los que ejercían de críticos y establecían juicios de valor sumándolos a los preceptivos nibil obstat y las preliminares advertencias de que nada se oponía a su publicación, en orden moral o religioso, y tampoco contra las leyes del reino. Se nota que el censor actúa movido por su excelente relación personal y, también, por alguna necesidad de llevarse bien con las víctimas propiciatorias de su actividad como memorión. A este respecto, es también sorprendente el calificativo que emplea para sí mismo,

27. Bouza (2012: 126-127).

28. Rojas (1640: IV). 
el de la Feliz Memoria, con el que será también conocido por sus contemporáneos y aun después de su muerte.

¿Pudo aprovecharse Luis Ramírez de Arellano de su condición de censor en su actividad como memorión? No lo sabemos, pero en cualquier caso es evidente que era alguien con quien no era muy recomendable — si se era escritor- llevarse mal. Quizás algún poeta, novelista o dramaturgo pudo temer que sus enojos pudieran traerle una denegación de la licencia de impresión, y quizás, por tanto, era preferible callar antes que denunciar. En cualquier caso, es evidente que Luis Ramírez de Arellano sabe elegir sus preferencias literarias, que son tanto Francisco de Rojas Zorrilla como Lope de Vega, a pesar de que este dirigiera ataques tan directos contra su persona y la de su hermano.

\section{Elogio de Lope de Vega con motivo de su muerte}

Con ocasión de la muerte de Lope de Vega —el 27 de agosto de 1635_, fueron muchos los escritores que colaboraron en un homenaje de composiciones poéticas dedicadas al gran escritor madrileño. De ahí resultó un volumen titulado Fama póstuma de Lope, donde se recogen elogios de docenas de autores, prácticamente la totalidad de los que tenían algún reconocimiento en la época. Entre ellos está un soneto de Luis Ramírez de Arellano que dice así:

Vive inmortal milagro peregrino, que aconteciste raro a nuestra Espańa en cuanto el mundo en ti se desengaña de que abriste a las Musas el camino.

Ya callará la envidia del destino obediente a su bárbara guadaña, vive, vive inmortal, pues te acompańa, toda una eternidad para divino.

De tu gran monumento voto sea cuanta del Pindo devoción ardiente fue en otro tiempo en aras y en altares.

Porque la envidia a su despecho vea, que asiste a Lope en culto reverente de tres orbes la fe, de cuatro mares. ${ }^{29}$

De nuevo se observa, tal y como hiciera con Francisco de Rojas Zorrilla, a un Luis Ramírez de Arellano agradecido y reconocedor de los méritos de un autor de teatro de la talla de Lope, pese a que sabe lo que pensaba públicamente

29. Vega (1779: 142). 
de él el autor de La dama boba o El príncipe perfecto. Recuérdese lo que tiempo antes señaló Lope de Vega sobre Ramírez de Arellano con tono despectivo en el prólogo a la Trecena parte de sus comedias. Bien es cierto que la familia debió encargar la escritura de la obra Los Ramírez de Arellano, como señalé en su momento, escrita mucho antes de su publicación en Zaragoza, en 1641, una vez muerto Lope de Vega. También sabemos, como señaló Luis Astrana Marín en el texto que he transcrito antes, extraído de su Vida azarosa de Lope de Vega, que ambos acabaron como buenos amigos: Lope entregando un poema a los Avisos para la muerte y aquel escribiendo en su elogio el poema transcrito en la Fama póstuma. Luis Astrana Marín extiende también la amistad a otro gran dramaturgo, poeta e hijo de editor, Juan Pérez de Montalbán.

\section{Los Avisos para la muerte de Luis Ramírez de Arellano. De los despertadores y las artes de morir}

Luis Ramírez de Arellano consiguió un gran éxito como memorión, fue censor de comedias, compuso algunas piezas poéticas y obtuvo grandes beneficios con una colección de poemas, bajo el título de Avisos para la muerte escritos por algunos ingenios de España, donde se limitó a recolectar un conjunto de composiciones poéticas de diversos escritores en un volumen con gran éxito de ventas. La primera edición que conozco es de 1634, en Madrid, por la viuda de Alonso Martín, impreso a costa de Alonso Pérez, librero de Su Majestad y que contó con la aprobación del maestro José de Valdivielso, también colaborador, quien ofreció a su publicación todo tipo de parabienes:

Libro aunque para estudios de la muerte, tiene mucho de libro de la vida, pues enseña los aciertos para la eterna, dulce y amarga como el que presentaron al lince de Pathmos, amarga como los que temen a la muerte por pena, y dulce a los que la esperan por desencanto.

Según la introducción a la obra, esta se compuso como respuesta a una iniciativa piadosa del padre Bernardo de Oviedo, por la que los ingenios escritores debían componer textos con los que ensayarse a morir. Transcribe composiciones de treinta autores, que son, en este orden, los siguientes:

Lope de Vega

Fr Diego Niseno

Antonio Mira de Amescua

José de Valdivielso

Juan Pérez de Montalbán

Dr. Felipe Godínez

Dr. Francisco de Quintana

Gaspar de Fuente y Vozmediano

M. Gabriel de Roa

M. Alonso de Alfaro 
Dr. Miguel Jerónimo Sanz

Antonio de León

Gabriel de Ilenao

Pedro Calderón de la Barca

Luis Vélez de Guevara

Francisco de Rojas Zorrilla

Antonio de Huerta

García de Salcedo Coronel

Antonio de Medina y Fonseca

Pedro de Bolívar y Guevara

Gabriel Bocángel y Unzueta

Antonio Pellicer Tovar

Pedro Rosete Niño

Martín de Figueroa Sarmiento

Alfonso de Batres

Juan Navarro de Espinosa

Francisco de Olivares y Figueroa

Luis Ramírez de Arellano

José de Villalobos

José Pellicer de Tovar

Cinco años después —en 1639—, una nueva edición añade a las de los autores citados otras composiciones de cinco autores más:

Francisco Bernardo de Quirós

Antonio de Castilla

Francisco Pérez de Amaral

Álvaro Cubillo

Bartolomé de Salazar y Luna.

Y otra reedición — de 1644-, cinco años después de la última, aparece con el mismo texto y los mismos autores. Según Inmaculada Osuna, la edición de 1648 sale a la luz poco después de la muerte del librero, y añade que quedaban aún en sus almacenes 1.600 ejemplares de la colección. Conocemos otras ediciones fuera de Castilla, en Valencia, Barcelona y especialmente Zaragoza — hasta cinco- desde 1634 hasta 1665. A partir de entonces, apareció publicada en Sevilla (1652, 1660 y 1697), en Lisboa y en Alcalá. Según Osuna, «en realidad, sólo a partir de 1660 las ediciones empezaron a espaciarse, hasta casi desaparecer en las tres últimas décadas del xVII; en el xviII no hubo más que dos (1772 y 1777), y por último, una en $1832 » .{ }^{30}$

El olfato editorial de Luis Ramírez de Arellano fue sin duda considerable, pues la obra siguió publicándose, después de su muerte, hasta mediados del siglo XIX. A este respecto, influyó no poco el renombre de sus autores, con Lope y

30. Ver Osuna (2009). 
Calderón a la cabeza, y otros muchos autores de primera fila en el xvir. Como nos recuerda Inmaculada Osuna, la mayoría de los escritores de la colección ya había publicado alguna obra y formaba parte, en algunos casos, de una nobleza de segunda categoría, como el propio Luis Ramírez de Arellano. ${ }^{31}$

La composición poética de Luis Ramírez de Arellano (El de la Feliz Memoria, según aparece en el texto) es un romance que comienza:

Primero, redentor mío

Que de la parca la furia

Al primer nativo polvo

Mi vida inútil reduzca

Primero que cuerpo y alma

Trágicamente desunan

Esta de lodo y fuego

Mortal y leve coyunda

Primero que mis cenizas

Breve mármol las incluya

Corto jaspe las posea

$\mathrm{Y}$ escaso bronce las cubra;

Primero, mi Dios, primero

Que caiga la arquitectura

De este breve mundo, de este

Monstruo de horrores y culpas

Primero, en fin, que el aliento

Los miembros vitales huya

Y que de mi vida torpe

El periodo se cumpla

Con voz pretendo, no sorda

Y con lágrimas, no mudas

Lograr la corta distancia

Que hay desde el lecho a la tumba

Escuchad piadoso un alma

Que con eficaz ternura

En este rubí sangriento

Sagradas clemencias busca

Una alma que arrepentida

Cuando el mundo le repudia

31. Ver Osuna (2009). 
Con suspiros os invoca

Y con fervor os saluda [...].

Todo el texto sigue con un tono imprecatorio parecido, en el que se alude al perdón por los pecados, con el desarrollo del conocido tema de la vanitas vanitatum y toda su tópica, que Inmaculada Osuna estudia magníficamente en su trabajo. Pero la misma estudiosa ofrece una indicación interesante: el texto está escrito no solo para devotos (como ejercicio de espiritualidad), sino también para laicos: «Se trata, desde luego, de una propuesta de devoción apta para laicos, sin afán totalizador, en tanto que bastante delimitada desde el punto de vista argumental, y sin las connotaciones de otros modelos de meditación y oración que reflejan hábitos monacales, como la liturgia de las Horas, o que requieren o al menos aconsejan el apartamiento de los quehaceres cotidianos, como los propios Ejercicios Espirituales ignacianos, con los que quizás estos poemas estén parcialmente relacionados». ${ }^{32}$

Antonio Rodríguez-Moñino ya señaló en su día el asombroso éxito editorial de la obra, ${ }^{33}$ aspecto en el que insiste también Edward M. Wilson. ${ }^{34}$ Sabemos que el librero Alfonso Pérez, padre de Juan Pérez de Montalbán, tuvo siempre fino olfato para los negocios editoriales, y por ello anduvo casi siempre detrás de Lope de Vega y de su círculo de escritores más cercano, así como vio con buenos ojos el empeño del compilador Luis Ramírez de Arellano, que tampoco andaba muy desencaminado en sus ideas y que fue quien poseía la licencia y privilegios que renovó tras los iniciales diez años en 1644.

Aunque la obra está llena de convencionalismos poéticos y morales, al uso de la época, como era preceptivo, la categoría de los autores le confiere al texto una calidad sobresaliente. Sin duda es un acierto colocar en primer lugar a Lope de Vega y no excluir a otros, más cercanos a Góngora (como Coronel). Cita Inmaculada Osuna entre las fuentes de los poemas y de la construcción de la obra a San Ignacio de Loyola, la literatura de avisos para la muerte, las danzas de la muerte medievales, fray García de Cisneros, fray Luis de Granada, Antonio de Molina o Pedro de Salazar, entre otros.

Tras la muerte de Luis Ramírez de Arellano, y una vez caducados los privilegios, la obra multiplicó sus ediciones, como he indicado, hasta mitad del siglo xIX. Pero es que, incluso en alguna ocasión, como la que señalo a continuación, se copian - literalmente - textos de la obra, haciéndolos pasar por propios.

Hay que advertir al respecto que en una obra titulada Vida del gran Thebandro español, su peregrinación e infortunios (1757) se da una descarada copia de versos y estrofas completas del poema original de Luis Ramírez de Arellano.

32. Osuna (2009).

33. Señala con su habitual detalle en el mismo estudio las diversas ediciones de la obra (1977: 473).

34. Wilson (1972: 79-105). 
Dice así el texto de la Vida del gran Thebandro, escrito por D. Antonio de Estrada Nava y Bustamante:

Primero, redentor mío Que de la parca la furia Al primer nativo polvo Mi vida inútil reduzca

Primero que cuerpo y alma

Trágicamente desnudan Esta de lodo y de fuego Mortal y leve coyunda

Primero que mis cenizas Breve mortal las incluya Corta tierra las posea Y escasa piedra las cubra;

Primero, mi Dios, primero

Que caiga la arquitectura De este breve mundo, de este Monstruo de horrores y culpas

Primero, en fin, que el aliento Los miembros vitales huya $\mathrm{Y}$ que de mi vida torpe El periodo se cumpla [...]. ${ }^{35}$

El plagio en El gran Thebandro de varias partes de la obra de Luis Ramírez de Arellano es descaradísimo. Pero lo curioso es que hay diversas alteraciones sobre el original, que aunque muy escasas, parecen indicar que el autor del plagio, Antonio de Estrada Nava y Bustamante, copia los versos de Luis Ramírez Arellano aprendidos de memoria. Compárese a este respecto los ahora transcritos con los originales de Luis Ramírez de Arellano y reproducidos en páginas anteriores. Curiosa manera de pagar con la misma moneda a quien durante años se adueñó con su memoria de las obras de otros. Es como si Antonio de Estrada Nava y Bustamante quisiera hacer las veces de Lope de Vega y tomar venganza de los abusos de Luis Ramírez de Arellano con las obras del mismísimo dramaturgo madrileño.

\section{Conclusiones}

Este trabajo ha tratado de situar la figura, muy poco conocida y estudiada, de un interesante personaje del mundo intelectual de la primera mitad del XVII, Luis

35. Estrada (1841: 398). 
Ramírez de Arellano. Miembro de la ilustre familia de los Ramírez de Arellano, con participación cultural muy relevante ya desde el siglo anterior (Juan Ramírez de Arellano, propiciador de la novela picaresca el Guitón Honofre; el protonotario y escritor Juan Ramírez de Lucena o su hijo Luis Ramírez de Lucena, además de su contemporánea sor Ana de la Trinidad, poetisa mística riojana), se ha intentado aquí recuperar algunos momentos importantes de su biografía y de su obra. No se trata de alguien que vivió al margen de los primeros espadas de la literatura de su época, sino que, aprovechando sus curiosas habilidades memorísticas, su situación social acomodada y las relaciones personales con personajes tan relevantes como Lope de Vega, a quien su propia familia encargó la obra de teatro Los Ramírez de Arellano, supo hacerse un hueco en el mundo cultural del XviI.

Generó odios entre los creadores, pero también amó la literatura como pocos, y propició aventuras editoriales de éxito — con un claro trasfondo económico que se hizo evidente-. Pudo también influir sobre sus contemporáneos como censor, protegiéndose de sus ataques, especialmente de Lope de Vega y de otros dramaturgos contemporáneos. A cambio, su actividad como memorión permitió que no se perdieran algunas obras relevantes de Lope, a cuya muerte dedicó una sentida composición poética, olvidando las duras palabras que el autor de La dama boba le había dirigido, así como la demanda judicial que promovió contra él.

También supo, como nadie antes, reunir bajo una empresa común —sus Avisos para la muerte - a los más notables poetas de su tiempo, que acudieron, a pesar de todo, a su llamado. Obra que, por cierto, es perfecto ejemplo de la concepción del mundo barroco por parte de los poetas de su época, ya no solo por el tema - la muerte - sino por la manera de abordarla. El simple hecho de haber podido reunir a personajes de tan diversa ascendencia y gusto poético es ya un éxito notable. Y ello en un momento en que las susceptibilidades, las filias y fobias poéticas son extremas.

Como anécdota curiosa, se recuerda que la composición de su autoría que incorporó a los Avisos fue objeto de plagio por parte de Antonio de Estrada Nava y Bustamante. De alguna manera el destino quiso jugarle una mala pasada al de "la feliz memoria» o de "la gran memoria», hermano del «memorilla», un personaje que es necesario añadir a la nómina de escritores y animadores de la vida cultural de nuestro gran Siglo de Oro de las letras. 


\section{Bibliografía}

Alvar EzQuerra, Alfredo, El duque de Lerma: corrupción y desmoralización en la España del siglo XVII, Madrid, La Esfera de los Libros, 2010.

Álvarez, Tomás (ed.), Ana de la Trinidad: poetisa, riojana y carmelita, Burgos, Monte Carmelo, 1992.

Álvarez y Baena, José Antonio, Hijos de Madrid ilustres en santidad, dignidades, armas, ciencias y artes, tomo III, Madrid, Oficina de Benito Cano, 1790.

Astrana y Marín, Luis, Vida azarosa de Lope de Vega, Barcelona, Editorial Juventud, 1941.

Bouza, Fernando, "Dásele licencia y privilegio». Don Quijote y la aprobación de libros en el siglo de Oro, Madrid, Akal, 2012, <http://www.academiaeditorial. $\mathrm{com} / w e b / d o n-q u i j o t e-y-l a-a p r o b a c i o n-d e-l i b r o s-e n-e l-s i g l o-d e-o r o />$, fecha de consulta: 15/03/2018.

Cabo Aseguinolaza, Fernando. "El Guitón Honofre’ y el modelo picaresco", Revista de Literatura, 48, 96 (1986), 367-386.

Canavaggio, Jean, "Aproximación al proceso Ezpeleta", Cervantes: Bulletin of the Cervantes Society of America, XVII, 1 (1997), 25-45, <https://cvc. cervantes.es/literatura/cervantistas/coloquios/cl_VII/cl_VII_05.pdf>, fecha de consulta: 15/03/2018.

Casás Fernández, Manuel, «Cervantes y Galicia. El Conde de Lemos, ilustre gallego, mecenas del inmortal autor del 'Quijote'», Boletín da Real Academia Galega, 285-288 (1945), 354-390.

Cáseda Teresa, Jesús, «El guitón Honofre, de Gregorio González: Una novela picaresca poco conocida", Kalakorikos: Revista para el estudio, defensa, protección y divulgación del patrimonio histórico, artístico y cultural de Calahorra y su entorno, 4 (1999), 281-288.

Criado de VAl, Manuel, «El Guitón Honofre: un eslabón entre celestinesca y picaresca», en La picaresca. Orígenes, textos y estructuras. Actas del I Congreso Internacional sobre la Picaresca, Madrid, Fundación Universitaria Española, 1979, 539-546.

Dixon, Víctor, "Tres textos tempranos de 'La dama boba'», Anuario Lope de Vega, 3 (1997), 51-66, <http://www.cervantesvirtual.com/obra-visor/trestextos-tempranos-de-la-dama-boba-de-lope-0/html/021 ca12a-82b2-11 dfacc7-002185ce6064_6.html>, fecha de consulta: 15/03/2018.

Estrada y Bustamante, Antonio de, Vida de el gran Thebandro, Madrid, Librería de Fermín Nicasio, 1741.

García ReIdy, Alejandro, “¿Competencia o colaboración? Memoriones, copistas y actores en un manuscrito de 'El príncipe perfecto (primera parte)'», en $E l$ patrimonio del teatro clásico español: actualidad y perspectivas: homenaje a Francisco Ruiz Ramón: actas selectas del Congreso del TC/12 Olmedo, 22 al 25 de julio de 2013, coord. por Germán Vega García-Luengos, Héctor Urzáiz Tortajada, Pedro Conde Parrado, 2015, 381-389, <http://www.academia. 
edu/16592913/_Competencia_o_colaboraci\%C3\%B3n_Memoriones_ copistas_y_actores_en_un_manuscrito_de_El_pr\%C3\%ADncipe_ perfecto_primera_parte_>, fecha de consulta: 15/03/2018.

Greer, Margaret R., «Manos teatrales: la historia contada por los manuscritos», TeaPal, 7 (2013), 516-531, <https://www.uqtr.ca/teatro/teapal/ TeaPalNum07Rep/29GreerMargaret.pdf>, fecha de consulta: 15/03/2018.

IbáÑez Rodríguez, Santiago, Armas Lerena, Noemí, Gómez Urdáñez, José Luis, Los señorios en La Rioja en el siglo XVII, Logroño, Instituto de Estudios Riojanos, 1996.

Millán Martínez, Juan Manuel, Martínez Soria, Carlos Julián (coords.), Diego Ramírez de Villaescusa: Obispo y mecenas, Cuenca, Ediciones de la Universidad de Castilla-La Mancha, 2009.

Morel D’Arleux, Antonia, «Los tratados de preparación a la muerte: aproximación metodológica", en Estado actual de los estudios sobre el Siglo de Oro: actas del II Congreso Internacional de Hispanistas del Siglo de Oro, coord. por Manuel García Martín, vol. 2, 1993, 719-734, <https://cvc.cervantes.es/ literatura/aiso/pdf/02/aiso_2_2_025.pdf>, fecha de consulta: 15/03/2018.

Moreno Ramírez de Arellano, Miguel Ángel, Señorio de Cameros y Condado de Aguilar: cuatro siglos de régimen señorial en La Rioja (1366-1733), Logroño, Instituto de Estudios Riojanos, 1992.

—, «La quiebra de la casa de Arellano en el contexto de la crisis señorial castellana de finales del siglo Xvi. Análisis de las causas determinantes del concurso de acreedores recaído sobre el Señorío de Cameros y Condado de Aguilar en 1592", Berceo, 114-115 (1988), 155-170.

Osuna, Inmaculada, «Los Avisos para la muerte de Luis Ramírez de Arellano», Via Spiritus, 16 (2009), 45-82.

Paz y Maliá, Antonio, Catálogo de las piezas de teatro que se conservan en el Departamento de Manuscritos de la Biblioteca Nacional, Madrid, Imp. del Colegio Nacional de Sordomudos y Ciegos, 1899.

Ramírez de Arellano, Diana, La comedia genealógica en Lope de Vega y edición crítica de Los Ramirez de Arellano, 1951 (Tesis Doctoral).

Rodríguez-Moñıno, Antonio, Manual bibliográfico de Cancioneros y Romanceros (siglo XVII), coord. por Arthur L. F. Askins, vol. III, n. ${ }^{\circ}$ 176, Madrid, Castalia, 1977.

Rojas Zorrilla, Francisco de, Primera parte de las comedias de don Francisco de Rojas Zorrilla, Madrid, por María de Quiñones, a costa de Pedro Coello, mercader de libros, 1640.

SuÁrez de Figueroa, Cristóbal, Plaza Universal de todas ciencias y artes, Madrid, Luisa Sánchez, 1615.

VV.AA., Jurisprudencia civil: Colección completa de las sentencias dictadas por el Tribunal Supremo en recursos de nulidad, casación civil e injusticia notoria y en materia de competencias desde la organización de aquéllos en 1838 hasta el dia, Madrid, Editorial Reus, 1838-1959. 
VV.AA., Constituciones sinodales del obispado de Barbastro, Zaragoza, Diego Dormer, 1656.

Vega, Lope de, Los Ramírez de Arellano, Zaragoza, Pedro Vergés, 1641.

-, Colección de obras sueltas, asi en prosa como en verso, de fray Lope de Vega y Carpio, del hábito de San Juan Madrid, Imprenta de Sancha, 1779.

-, Comedias escogidas de Félix Lope de Vega y Carpio, ed. de J.E. Hartzenbusch, Madrid, Rivadeneyra, 1869.

—, "La Arcadia», en Obras de Lope de Vega, ed. de Marcelino Menéndez Pelayo, Madrid, Atlas (BAE, CLXXXVIII), 1965.

Wilson, Edward Meryon, «Un romance ascético de Calderón: 'Agora, Señor, agora...'", Boletín de la Real Academia Española, tomo LII, cuaderno 195, 1972, 79-105.

ZugaSTI, Miguel, «Autoridad textual y piratería, con sombras de memorión al fondo, en las dos primeras ediciones de 'El poder de la amistad' (1654), de Agustín Moreto", Boletín de la Real Academia Española, 91, 303 (2011), 169-191, <http://data.cervantesvirtual.com/manifestation/780004>, fecha de consulta: 15/03/2018.

\section{Fuentes archivisticas}

Archivo General de Andalucía: ES.41188/3//3761.9 y 3761.5. Inventario judicial de los bienes de Gil Ramirez de Arellano, y documentación diversas sobre el pleito con sus acreedores. 1618-1622. 
